\title{
Editorial
}

\section{Scientific Programming Tools for Water Management}

\author{
Francisco J. Alcalá $\mathbb{D},{ }^{1}$ Jaime Martínez-Valderrama $\mathbb{D}^{2}{ }^{2}$ Francisco Gomáriz-Castillo $\mathbb{D},,^{3,4}$ \\ Carlos G. Hernández $\mathbb{D},{ }^{5}$ and José M. Cecilia ${ }^{(\mathbb{D}}{ }^{6}$ \\ ${ }^{1}$ Instituto Geológico y Minero de España (IGME), Madrid 28003, Spain \\ ${ }^{2}$ Multidisciplinary Institute for Environment Studies 'Ramón Margalef, University of Alicante, San Vicente del Raspeig, \\ Alicante 03690, Spain \\ ${ }^{3}$ Department of Geography, University of Murcia, Murcia 30100, Spain \\ ${ }^{4}$ Euro-Mediterranean Water Institute (IEA), Murcia 30100, Spain \\ ${ }^{5}$ Departamento de Producción Agraria, Universidad Politécnica de Madrid, Madrid 28040, Spain \\ ${ }^{6}$ Department of Computer Engineering (DISCA), Universitat Politècnica de València, Valencia 46022, Spain
}

Correspondence should be addressed to Francisco J. Alcalá; fj.alcala@igme.es

Received 18 May 2021; Accepted 18 May 2021; Published 23 July 2021

Copyright (c) 2021 Francisco J. Alcalá et al. This is an open access article distributed under the Creative Commons Attribution License, which permits unrestricted use, distribution, and reproduction in any medium, provided the original work is properly cited.

\begin{abstract}
This special issue delivers a platform in which researchers expose intersections between algorithm design, software platforms, and hardware architectures to deal with emerging challenges in the scientific field of management of water and water-dependent resources. Since the call for papers was announced in June 2019, this special issue has received 10 manuscripts. After a rigorous review process, 6 papers have been finally accepted for publication. Published papers deal with groundwater quality monitoring, coastal groundwater-dependent irrigation agriculture, desertification risk, water recovery from tailings, future scenarios of water resources, and vulnerability of coastal aquifers.
\end{abstract}

\section{Introduction}

One of the main humanity challenges is management of water and water-dependent resources. Global climatic driving forces determine the water availability and renewability rates of water-dependent resources such as soil, rangelands, crops, livestock, and similar others. The management of water and water-dependent resources is mandatory to cope with ecosystem preservation and human development. However, many of the terrestrial socioecological systems are typically sparse-data areas where the capability to adequately characterize the nonlinear processes that govern the dynamics of water and water-dependent resources is limited. Climate may determine the design of a computation platform. Many of the computational tools designed for humid and temperate regions often fail when trying to reproduce some complex human and environmental interactions that occur in drylands. In general, a lack of computational tools for modelling of water and waterdependent resources in the literature is observed.
The integration of the latest breakthroughs in geology, climatology, hydrology, agronomy, mining, and biotechnology from one side and high-performance computing, artificial intelligence, and computational modelling to the other has enabled remarkable advances in the field of water management. By merging these developments, scientists have started to create new strategies to cope with the consequences of global climatic forces and human action, such as water scarcity, ecosystem degradation, and decreasing renewability rates of water-dependent resources.

These scientific applications typically require big datasets and complex simulations to adequately characterize the nonlinear processes that govern the dynamics of water. Highly intensive computational strategies could greatly benefit from increased scientific computational resources to reproduce the complex environmental and human interactions that occur in water bodies and their associated ecosystems and dependent resources. All these scientific and programming advances are combined to provide innovative solutions to deep-seated problems for 
society, especially with respect to forecasting and uncertainty analysis.

This special issue aims to deliver a platform. On the platform, researchers expose how the intersections between algorithm design, software platforms, and hardware architectures can be used to deal with emerging challenges in the scientific field of management of water and water-dependent resources. At the same time, this special issue showcases the main trends in scientific parallel processing, algorithm definition, and problem-domain requirements to anticipate future solutions which could be translated into real societal benefits. This special issue includes original research articles that describe specific computational tools related to natural and nonconventional water source management, optimization of water in agriculture, industrial and mining, and the dynamics of water-dependent resources.

Once the call for papers was announced in June 2019, this special issue has attracted attention. In total, 10 manuscripts were received. After a rigorous review process, 6 papers have been finally accepted for publication. To gain a better insight into the essence of the special issue, we offer brief highlights of the published papers in Section 2.

\section{Published Papers}

The paper "A New Clustering Algorithm and Its Application in Assessing the Quality of Underground Water" [1] introduces a new concept of "epsilon radius neighbours" in cluster analysis. Based on "epsilon radius neighbours," a new clustering algorithm in which the epsilon radius value is adapted to the characteristics of each cluster in the current partition is proposed for groundwater quality monitoring. Through this application, the authors found that the new algorithm might provide valuable reference information for groundwater quality monitoring management.

The paper "AQUACOAST: A Simulation Tool to Explore Coastal Groundwater and Irrigation Farming Interactions" [2] introduces a tool to analyse the impact of apparently unrelated factors such as the prices of crops, subsidies, or exploitation costs on the advance of saltwater intrusion, a great threat to coastal groundwater-dependent irrigation agriculture systems. The tool implements a system dynamics model in Vensim software that considers the integration of hydrological, agronomic, and economic drivers, and a Venapp push-button interface that allow users access to a Vensim model without going through the Vensim modelling environment.

The paper "Flow Enhancement of Mineral Pastes to Increase Water Recovery in Tailings: A Matlab-Based Imaging Processing Tool" [3] determines how water content affects the flow behaviour and depositional geometry of tailings and silica flour pastes in the mining copper industry. The modelling results indicate that the new technique can be incorporated to determine the proper solid content and modifiers for a given fluidity requirement. In general, the techniques are aimed at reducing current high water losses by evaporation and percolation during mineral recovering practices.
The paper "A Statistical Tool to Generate Potential Future Climate Scenarios for Hydrology Applications" [4] introduces GROUNDS to generate potential future climate scenarios in water resources systems of different typology and size (river basins, aquifers, mountain ranges, and countries) from historical and regional climate model information. The tool generates future series of precipitation, temperature, and potential evapotranspiration and uses different approaches and statistical correction techniques to generate individual local projections and ensembles of them. The tool is also useful for quantifying the uncertainties of future scenarios by combining them with stochastic weather generators.

The paper "SAT: A Software for Assessing the Risk of Desertification in Spain" [5] presents SAT, a decision support system for assessing the risk of desertification in Spain. SAT relies on three versions of a generic desertification model that integrates economics and ecology under the predator-prey paradigm. The models have been programmed using Vensim, a software to build and simulate system dynamics models. Through Visual Basic programming, these models are operated from the Excel environment. Other specially designed tools have been coupled to assess the risk of desertification and determine the ranking of the most influential factors.

The paper "GIS-SWIAS: Tool to Summarize Seawater Intrusion Status and Vulnerability at Aquifer Scale" [6] introduces GIS-SWIAS, an ArcGIS ArcToolbox to analyse seawater intrusion (SWI) status and vulnerability at aquifer scale. The tool uses georeferenced information and provides results in terms of reports and images of the SWI evolution over time. Depending on the data coverage, the tool can be applied to provide an initial picture of historical SWI or a rational quantification for detailed SWI management. The tool enables researchers and technicians to assess SWI dynamics and aquifer resilience under different management scenarios including adaptation strategies to potential future scenarios.

\section{Conclusions}

The guest editors envision that the published papers in this special issue would be of interest to researchers and practitioners and help identify further research routes. We also hope that the readers can find the material of this special issue both interesting and inspiring when exploring the field of management of water and water-dependent resources.

\section{Conflicts of Interest}

The editors declare that they have no conflicts of interest.

\section{Acknowledgments}

The editors also express gratitude to all authors for their submissions to this special issue. The editors would also wish to thank the editorial board for the opportunity to edit this special issue and for providing valuable suggestions to improve the selection of research manuscripts. 
Francisco J. Alcalá

Jaime Martínez-Valderrama Francisco Gomáriz-Castillo

Carlos G. Hernández

José M. Cecilia

\section{References}

[1] T. Vo-Van, A. Nguyen-Hai, M. V. Tat-Hong, and T. NguyenTrang, "A new clustering algorithm and its application in assessing the quality of Underground water," Scientific Programming, vol. 2020, Article ID 6458576, 12 pages, 2020.

[2] J. Martínez-Valderrama, J. Ibáñez, and F. J. Alcalá, “AQUACOAST: a simulation tool to Explore coastal groundwater and irrigation farming interactions," Scientific Programming, vol. 2020, Article ID 9092829, 20 pages, 2020.

[3] S. L. Mondaca, C. A. Leiva, C. A. Acuña, and E. A. Serey, "Flow enhancement of mineral pastes to Increase water recovery in tailings: a matlab-based imaging processing tool," Scientific Programming, vol. 2020, Article ID 5607242, 9 pages, 2020.

[4] A. J. Collados-Lara, D. Pulido-Velazquez, and E. PardoIgúzquiza, "A statistical tool to generate potential future climate scenarios for hydrology applications," Scientific Programming, vol. 2020, Article ID 8847571, 11 pages, 2020.

[5] J. Martínez-Valderrama, J. Ibáñez, F. J. Alcalá, and S. Martínez, "SAT: a software for assessing the risk of desertification in Spain," Scientific Programming, vol. 2020, Article ID 7563928, 12 pages, 2020.

[6] L. Baena-Ruiz and D. Pulido-Velazquez, "GIS-SWIAS: tool to summarize seawater intrusion status and vulnerability at aquifer Scale," Scientific Programming, vol. 2021, Article ID 8818634, 15 pages, 2021. 